\title{
Third-Grade English Second Language teachers' vocabulary development practices
}

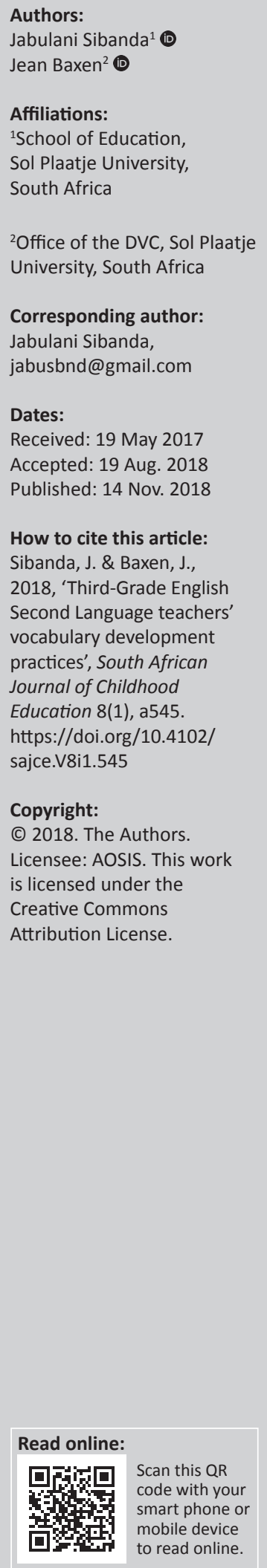

Background: This article investigated the potential of Grade 3 English Second Language (ESL) teachers' vocabulary development practices to equip learners in English-deprived environments with English vocabulary requisite for transition to Grade 4 where English is the Language of Learning and Teaching and where learning to read gives way to reading to learn.

Aim: This study sought to document and interrogate incidental and explicit Grade 3 ESL teachers' vocabulary development practices vis-à-vis learners' vocabulary needs.

Setting: Three classrooms from one township and two diverse rural schools in three different districts of the Eastern Cape province of South Africa were observed.

Methods: The case study sourced qualitative data through video and field notes recorded in classroom observations in 10 English First Additional Language classes for each teacher. Quantitative data on teacher talk vocabulary exposure and recycling were generated using the AntConc 3.2.4 software.

Results: The study found that the incidental vocabulary development was compromised by low English language exposure occasioned by teachers' frequent recourse to the Home Language, little word recycling in classroom talk and lack of rich contexts in which words were encountered. Explicit vocabulary instructional practices mostly drew learners' attention to novel words and had a narrow range of strategies dealing with word meanings.

Conclusion: In view of the manifest lack of a robust vocabulary development programme among ESL teachers, the study recommends planned and deliberate attention to vocabulary development on the teachers' part and a reconsideration of the learners' vocabulary needs and learner meaningful engagement in vocabulary development.

\section{Introduction}

In South Africa, learners' Home Language (HL) is the Language of Learning and Teaching (LoLT) in the Foundation Phase (FP) covering Grades R-3. The LoLT for 80\% of the South African learners (Howie et al. 2008:8) shifts from an African language to English as First Additional Language (FAL) the moment the learners get to Grade 4, the beginning grade for the Intermediate Phase (IP) covering Grades 4-6. Another shift is the change in the focus of reading from learning to read (which is the acquisition of the mechanical process of reading) to reading to learn (which is the employment of one's reading competence to extract meaning from informational texts). The shift in reading foci is largely credited with what has been designated as the 'fourth grade slump', denoting a '...sudden drop-off between third and fourth grade in the reading scores...' (Hirsch 2003:10), a global trend that is as characteristic among HL speakers as it is among FAL learners. Wright (2012:353) posits that, '[B]y fourth grade, students with limited vocabulary knowledge are likely to slump in reading comprehension'. This implies the need for learners to develop sufficient vocabulary repertoire in the FP in preparation for the vocabulary demands of Grade 4 occasioned by the two transitions. Consistent with this need is the recommendation by the current Department of Basic Education (DBE) official curriculum, the Curriculum and Assessment Policy Statement (CAPS) (2011), that learners:

\footnotetext{
... must reach a high level of competence in English by the end of Grade 3, and they need to be able to read and write well in English. For these reasons, their progress in literacy must be accelerated in Grades 2 and 3. (p. 11)
}

Insufficient English vocabulary is a severe handicap for second language (L2) readers. The symbiotic relationship between the knowledge of English vocabulary and the development of reading strategies is manifest in their mutual causation. The massive vocabulary requisite for reading proficiency and learning necessitates a robust, sustained, explicit and principled approach 
to classroom vocabulary development. Linse (2005) identifies, as a realistic target under optimal conditions, L2 learners' annual acquisition of 500 words. The burden of English classroom vocabulary development is more so in instances where learners' HL is not English (as is true for most Grade 4 learners in South Africa), and where environments lack sound English language infrastructure for learners to fall back on. The responsibility of inculcating the massive requisite vocabulary largely devolves to the teacher.

This article is based on an aspect of a larger study that investigated the English vocabulary needs of English FAL Grade 3 learners transitioning to Grade 4, and the extent to which they were met. The results reported in this article focus specifically on vocabulary-related classroom practices of three Grade 3 isiXhosa-speaking teachers in English FAL lessons. Three questions framed the study:

- What English vocabulary development pedagogical practices manifest in Grade 3 English FAL classes?

- What is the implication of teachers' vocabulary development practices to lexical acquisition and learning among Grade 3 learners as they transition to Grade 4?

- To what extent are the observed practices consistent with what the study views as a comprehensive vocabulary instruction programme?

\section{Study context}

The learners within the study context experienced multiple disadvantages. Some of them were the low language proficiency of their teachers, poor language infrastructure, inadequate material provisions, among others. Such disadvantages required compensation in the form of sound instructional practices. Research has documented low English proficiency among many South African teachers (Krügel \& Fourie 2014; Nel \& Muller 2010) and concomitant detrimental effects on learners, an observation confirmed in the larger study from which this article derives. The Eastern Cape province of South Africa, where this study was conducted, is known for its rural poverty and education underperformance at Grade 12 level relative to other provinces (DBE 2016). This meant that learners from the township and rural schools, who constituted the study sample, had very little language infrastructure and virtually no interaction with English HL users. Even the classroom space was not adequately resourced to support vocabulary development (Sibanda 2017). The pervasiveness of such poorly resourced, English-deprived environments necessitated a determination of the teaching practices manifest in the classrooms. What is more, although vocabulary demands on learners hailing from English HL and English FAL contexts are the same, their learning trajectories are different and merit different strategies and teaching practices. Grabe and Stoller (2011) identified 14 such differences under three dimensions, namely linguistic and processing differences, individual and experiential differences, and sociocultural and institutional differences.
The notion of practice and that of vocabulary development constitute the underlying theoretical framework for the study, with the notion of practice seen through the works of Kemmis (2009) and Schatzki (2002) and that of vocabulary development being interrogated through the Texas Reading Initiative's (2002) effective vocabulary instruction programme.

\section{The notion of practice}

Practice is not easy to determine owing to its fluidity. Green (2009) rightly observes that the concept of practice has narrowly been used to refer to what people do within a context. This conflates practice with performativity and not with praxis. Kemmis (2009) sees practice as comprising 'sayings', 'doings' and 'relatings'. Doings relate to externally observable behaviour, performances or activities manifested by the practitioner; relatings denote the interactions engaged in by those involved in the practice and their defining roles; and sayings concern the discourse or language that is used within the interaction and what practitioners say as they engage in the practice. The present study sought to determine vocabulary development practices from what teachers did, what they said and how they related with their learners. The three constituents of practice, therefore, became an organising framework for the interpretation of vocabulary development practices among Grade 3 teachers. The three are reflected in Schatzki's (2002) arrangement of language (sayings), arrangement of actions (doings) and arrangement of people (relatings).

\section{The notion of vocabulary development}

Vocabulary development can be conceived in two ways, namely facilitating vocabulary acquisition or fostering vocabulary learning. The former constitutes opportunities that the teacher creates from which learners incidentally and implicitly make gains to their vocabulary repertoire. In this respect, context is critical to vocabulary acquisition. The latter is used in this study to denote explicit and deliberate strategies that teachers used to ensure learners learnt new words. For this study, the term 'vocabulary development' accommodates opportunities availed for both the incidental acquisition and explicit learning of words by learners.

A key aspect of incidental vocabulary acquisition is the quality and quantity of vocabulary exposure and recycling, particularly for non-cognate languages, as was the case with this study. Joe (2010:117) concludes from longitudinal case study data that '... frequency of encounters contributes more to vocabulary learning than contextual richness does'. Frequent word exposure within rich contexts, coupled with opportunities for immediate or long-term subsequent use of the words, will ensure significant gain in vocabulary. Cognitive processing of words, their storage, activation and retrieval, is expedited through frequency of word exposure (Zhu 2015). While extensive vocabulary coverage is important, Hinkel (2007:6) advocates vocabulary instruction that does not go 'a mile wide but only an inch 
deep', for learners to own a word. Sacrificing depth for breadth in vocabulary development where many words are used only once or twice is itself counterproductive. Both input and output modalities allow for robust representations of words in the lexicon to enhance vocabulary acquisition. Cognitive engagement with meaningful, linguistic rich tasks, which aligns with Laufer and Hulstijn's (2001) proposed involvement load hypothesis, enhances vocabulary acquisition opportunities.

The study further classifies explicit vocabulary development practices into those that merely sought to draw learners' attention to key or novel words without further mediating their meaning and use on the one hand, and those that mediated word meaning or word use knowledge on the other hand. The former, which we refer to as 'flagging' strategies, do not extend beyond mere word recognition at the sensory level, be it at the phonological or orthographic level. The latter classification was that of vocabulary episodes, which Wright (2012:353) defines as '...interaction in which the teacher discussed the meaning of a word with students at any point throughout the observation period'.

Explicit attention to word form is foundational to long-term retention. Joe (2010) posits a relationship between semantic elaboration and word recall. Researchers like Biemiller (2005) have documented the meagre percentage of vocabulary instructional time and the absence of systematic, explicit vocabulary instruction in schools within second language contexts. Traditionally, it was assumed that word instruction would be taken care of by the glossary and the dictionary, and instruction was in the form of a quick oral definition. Such on-the-fly word exposures hardly translated to longterm word learning (Nagy 2005).

\section{Effective vocabulary instruction programme}

A framework outlining effective vocabulary instruction is instructive for a study establishing practices related to vocabulary development. According to the Texas Reading Initiative (2002), an effective vocabulary instruction programme should provide word learning opportunities through wide reading, exposure to high-quality oral language, promotion of word consciousness, direct teaching of word meanings and instruction in independent word learning strategies. Christ and Wang (2010) similarly identified exposure to new vocabulary, self-motivation and engagement, multiple exposures to new words offering contextual and definitional information, and use of independent word learning strategies as requisites to learner word learning.

How much students read and are read to determines the vocabulary gains they will make. The Texas Reading Initiative (2002) notes, in HL contexts, that learners need to acquire between 2000 and 3000 words per year to keep up. It further notes that for disadvantaged learners to catch up, the rate should be higher. Exclusive reliance on either explicit or implicit vocabulary development would not adequately attend to learners' vocabulary needs. The cumulative effect of regular vocabulary exposure from learners' self-reading
TABLE 1: Framework for vocabulary practices analysis.

\begin{tabular}{llll}
\hline $\begin{array}{l}\text { Nature of } \\
\text { vocabulary } \\
\text { development }\end{array}$ & $\begin{array}{l}\text { Manifestation of } \\
\text { nature of vocabulary } \\
\text { instruction }\end{array}$ & $\begin{array}{l}\text { Related aspects of } \\
\text { comprehensive vocabulary } \\
\text { instruction (Texas Reading } \\
\text { Initiative 2002) }\end{array}$ & $\begin{array}{l}\text { Link with } \\
\text { Kemmis' (2009) } \\
\text { elements }\end{array}$ \\
\hline Incidental & $\begin{array}{l}\text { Quantity of } \\
\text { vocabulary exposure } \\
\text { Vocabulary recycling }\end{array}$ & Encouraging wide reading & doings/relatings \\
& $\begin{array}{l}\text { Richness of contexts } \\
\text { in which vocabulary } \\
\text { is exposed }\end{array}$ & $\begin{array}{l}\text { Exposure to high-quality } \\
\text { oral language }\end{array}$ & sayings/doings \\
Explicit & Flagging strategies & $\begin{array}{l}\text { Promotion of word } \\
\text { consciousness }\end{array}$ & doings/sayings \\
& Vocabulary episodes & $\begin{array}{l}\text { Teaching word meaning } \\
\text { directly }\end{array}$ & doings \\
& & $\begin{array}{l}\text { Teaching independent } \\
\text { word learning strategies }\end{array}$ & doings/relatings \\
\hline
\end{tabular}

and being read to can be phenomenal, provided the right texts at both the independent and instructional reading levels are used.

Notwithstanding the immense gains emanating from extensive reading, learners in the study context were still on the learning to read trajectory and so needed quality exposure to oral language in the target language (English) that approximated written and literate English lexically and syntactically (Texas Reading Initiative 2002). Story-telling could be utilised to afford such exposure.

For word consciousness, activities where learners get a feel for the distinction between written language and ordinary conversation are requisite. Learners' play with words enhances word consciousness. Techniques for independent word learning would include dictionary use, guessing word meanings from contextual use and the use of affixes. Table 1 combines all these theoretical ideas into a comprehensive framework for analysing vocabulary instructional practices.

\section{Methodology}

\section{Sample}

Although the larger study from which this article derives was based on 10 teachers from eight schools, it presents practices of three, who represented the diversity of the 10 in terms of qualifications, experience and school location. The teachers are given the pseudonyms Anne, Beauty and Carol. In terms of qualifications and experience, Anne held a Master's degree and over 20 years of teaching experience, Beauty had a Bachelor of Education degree and $0-5$ years of teaching experience and Carol had an Advanced Certificate in Education (ACE) and over 20 years of teaching experience. Anne taught in a township school, whereas Carol and Beauty taught in rural schools, whose rurality was diverse in terms of proximity to the urban area as well as infrastructure and resource provisions. The sampling of a sample of the larger study allowed for greater depth in reporting teachers' practices.

\section{Procedure}

English vocabulary instructional practices derived from both the three video-recorded lessons for each teacher, and 
observations captured through field notes for lessons that were not video-recorded. All lessons were observed during English reading sessions with the assumption that vocabulary development practices would be most manifest in reading sessions. Field notes were captured in accordance with categories on the framework for vocabulary practices analysis in Table 1. The qualitative dimension of the study was in the description of observed practices in both the video-recorded and unrecorded lessons, while the quantitative dimension was in the representation of English vocabulary exposed to the learners and its recycling within 5 min intervals. For the quantitative dimension, the AntConc 3.2.4 concordance software was used to determine word exposure and word recycling. For word recycling, 60 high-frequency words (HFWs), which Sibanda and Baxen (2016) determined as must-know words for learners transitioning to Grade 4 in the South African context, were considered.

Incidental vocabulary development practices were examined under two of the Texas Reading Initiative's (2002) five aspects: extensive reading and exposure to high-quality oral language input. Quantity of word exposure, richness of context in which the exposure was made and HFWs recycling were interrogated. Explicit pedagogical practices were investigated under the other three aspects of the Texas Reading Initiative's (2002) comprehensive vocabulary instruction programme, namely word consciousness (which took the form of word flagging strategies), direct teaching of word meanings (in the form of vocabulary episodes) and instruction in independent word learning strategies. Word consciousness, through word flagging strategies, drew learners' attention to the graphophonic aspects of words (which largely developed word recognition) and vocabulary meaning episodes were largely meant to develop passive and active word knowledge, thereby covering the whole spectrum of word recognition, passive word knowledge and active word knowledge.

\section{Ethics}

All ethical protocols including the granting of informed consent for conducting the study, guaranteeing participants anonymity and confidentiality, and ensuring no harm to participants were observed. Video-recording of lessons was consented to on condition that the videos would not be used for any other purposes than the research purpose, and would be deleted thereafter.

\section{Results}

Results presentation follows the broad categories of incidental and explicit vocabulary development divided into the five aspects of a comprehensive vocabulary development programme as envisaged by the Texas Reading Initiative (2002).

\section{Incidental vocabulary development practices}

This section documents the practices that had the potential to indirectly develop learners' word acquisition.

\section{English vocabulary exposure and recycling in classroom talk}

The word count, done by the AntConc 3.2.4 software on the three 45-min recorded lessons for each teacher, was in terms of both word tokens and word types. While word types counted each single word once no matter how many times it appeared in the text, word tokens counted each word as many times as it appeared. Much token-type variation was indicative of many different words being used without being repeated, and little variation signalled use of fewer words repeatedly. The greater the token-type variability, the greater the word recycling. Ideally, the Type-Token Ratio (TTR) should be about $51.1 \%$ calculated as (number of types/number of tokens) $\times 100$ (see Table 2). While acknowledging the sensitivity of TTR to text length (Koizumi 2012) where longer texts were more likely to have greater variability than shorter texts, the TTR was meant to give an indication of frequency and variability in teacher talk vocabulary.

That the highest quantity of English words exposed to learners in $45 \times 3$ min was 4036 tokens (an average of 1345 words per lesson) evinced low exposure to English vocabulary. The highest TTR of 23.8 fell even below half the $51.1 \%$ expected signifying low recycling of vocabulary. The quantity of English vocabulary exposure was compromised by the over-reliance on the learners' HL by both the teachers and learners. While the TTR gave some indication of the frequency with which some words recurred (word recycling), it did not indicate whether the word was a mere repetition several times at the same point in the lesson, which would not constitute recycling. A systematic way of capturing the extent of the HFWs' recycling, to allow for repetitive exposure, was employed to determine how many of the 60 HFWs were recycled in 5 min intervals (see Table 3). The $45 \mathrm{~min}$ lessons had nine 5-min intervals and, using our discretion, a word had to recur in at least four of the nine intervals to qualify for a sufficiently recycled word to allow for rudimentary acquisition. Recycling of words at regular intervals was needed to entrench the words into long-term memory (Linse 2005).

The 60 HFWs had a fair mix of content and function words and it was interesting to note that of the $15 / 60$ (25\%) recycled words, only one, 'look', was a content word.

TABLE 2: The type-token ratio of classroom talk.

\begin{tabular}{lccc}
\hline Teacher & Type & Token & \% Type-token ratio \\
\hline Anne & 916 & 3843 & 23.8 \\
Beauty & 312 & 1847 & 16.9 \\
Carol & 821 & 4036 & 20.3 \\
\hline
\end{tabular}

$\%$, Percentage.

TABLE 3: Part of 60 high-frequency words recycled in at least four of the nine intervals.

\begin{tabular}{lll}
\hline Sufficiently recycled & Words from the 60 HFWs & Number of words/60 \\
\hline In all 3 teachers' talk & and, you, do, what, is, for, on & $7 / 60=11.7 \%$ \\
In 2 teachers' talk & it, that, out, not, look, again & $6 / 60=10 \%$ \\
In just 1 teacher's talk & can, because & $2 / 60=3.3 \%$ \\
\hline
\end{tabular}

HFWs, high-frequency words. 
This was possibly owing to function words abounding in speech and writing as they bring grammaticality to, and show the structural relations of, some words, which are the function words. It was less likely, therefore, that their use was deliberate on the teachers' part. Word recycling, especially content word recurrence was, therefore, lacking.

In the classes observed, there was a manifest lack of a variety of books and no time was set aside for reading or being read to. Opportunities to expose learners to new words and recycle them was lost in the use of the first language for sayings like giving commendation, classroom control, beginning or ending the lesson, giving instructions and asking for information etc. These routine classroom activities were open to multiple ways of communication. Calling learners to silence and attention could have been done in half a dozen ways that could be repeated often until all the vocabulary involved was part of learners' own vocabulary.

\section{Explicit vocabulary instruction}

Reported here are practices that deliberately focused on developing word knowledge among the learners.

\section{Word consciousness activities}

Word consciousness was achieved by the word flagging strategies or strategies for drawing attention to novel or key English words. Noticing words precedes learning word meanings (Christ \& Wang 2010).

Repeated word reading: This was the most prevalent strategy used in every English FAL lesson. It took the form of choral word reading after the teacher to note how the word is pronounced and how it looks. Beauty had a word list on the board that she pointed to and read for learners to read after her and learners would continue to read it as many times as she pointed at it; usually twice or thrice (depending on the length of the word that she evidently took to imply its complexity). This was typical of all the teachers and the whole class would stand close to the board for such choral repeated readings. The smallest word list thus read was six (Anne) and the biggest list was 23 words (Beauty).

There was little variation to this pattern, as when Anne combined the choral repeated word reading with word spelling. The learners read each word twice after which she read out each letter making up the word while the learners said it after her. After the reading of the last letter, she read the whole word again and had the learners repeat it. The other variation manifest once in Carol's class was when the choral repeated reading was led by a more competent learner after the teacher's initial demonstration. The variations were too minor to warrant being a different form of the strategy. Sometimes what was meant to be word reading degenerated into word saying for some learners who would merely parrot the teachers' reading when they were not even facing the board.
Repeated word saying: In repeated word saying, learners relied on the auditory rather than the visual form of the word from the teacher. The teacher said the word or phrase more times than the learners would repeat after her. Anne on one occasion repeated the words 'present continuous' five times with the learners repeating after her thrice. She then had them repeat the word 'continuous' on its own twice. Word or phrase repetitions were done consecutively and not recycled within intervals in discourse. In only a single observed instance did Carol and Beauty end up writing the repeated words. The word was supposed to be known at the aural level. Word selection did not seem to follow specific criteria. That learners were not told about the purpose repeated word readings and sayings were meant to serve, whether pronunciation or spelling, made it doubtful that the formal aspects intended to be recognised in a word were actually recognised.

Word spelling: Word spelling was prevalent especially in Carol's class where repeated word reading preceded word spelling. She would just say 'how to spell...' and the learners, while looking at the word on the chalkboard or chart, would spell the word in unison. Beauty would ask learners to look at the word momentarily and then ask them to close their eyes and spell the words in chorus. There was not much spelling activity in Anne's class.

Word stress or emphasis: All three teachers used stress or word emphasis to draw attention to particular words within a context. This was the only 'word flagging' strategy that was contextualised. Beauty stressed the word 'wearing' in the following exchange:

Teacher: What is the baby wearing, wearing?

Teacher: What is the baby wearing?

Learners: The baby is wearing a dress.

The 'wearing' was meant to elicit a response in which the same word was used. Sometimes the stress was meant to model pronunciation or to distinguish one word from a similar sounding one. The stress/emphasis took the form of higher pitch or longer stress. Sometimes the word was enunciated slowly emphasising its syllables, for example, 'vo-we-ls'. The stress was meant to engender word recognition at the phonological level.

Segmentation of polysyllabic words: The segmentation of polysyllabic words was only used by Beauty and Anne and once and twice, respectively, for that matter. It almost straddled between a flagging strategy and a vocabulary episode in that something was done to the word learners' attention was being drawn to. Anne's syllabification was 'toothbrush, tooth, brush, tooth, brush, toothbrush'. Word knowledge was facilitated at the orthographic (where the word was written), phonological and morphological levels. Even the semantic dimension was hinted at in the segmentation of compound words like toothbrush. 
Leaving out blanks for learners to complete: The strategy was exclusive to Carol who habitually would have exchanges like the following:

Teacher: There is a dog that is barking

Teacher: This is a dog and the dog is ....

Class: Barking

The teacher's stem or frame of the response gave the clue of what word was being sought. Sentence reformulation was meant to provide sufficient clues to the word she wanted noticed.

What was common about the use of all the flagging strategies was the choral nature of learner responses and their decontextualised nature. There was a manifest overemphasis on nouns on account of the ease with which their meanings could be demonstrated at the expense of novel words in other word classes. Sometimes words that were too basic, like 'cow', were isolated for direct instruction, which raised the question about the criteria for word selection and whether word choice had more to do with teacher convenience than learner needs. Though much concrete vocabulary was drawn attention to, there was very little done to represent the words in some concrete form, be it miming, use of pictures, diagrams or realia or even gestures.

\section{Explicit word instruction}

Sometimes isolation of words for direct teaching during a reading session detracted from textual comprehension. Sometimes the words taught in isolation were not highlighted when they were encountered in text for consolidation. Some unfamiliar words in a text were isolated for direct instruction when they were not terribly important to textual comprehension. Graves (2006:69-70) identifies a cocktail of effective vocabulary instructional strategies including both definitional and contextual information, involving students in active and deep processing of the words, providing students with multiple exposures to the word, reviewing, rehearsing and reminding students about the word in various contexts over time, involving students in discussions of the word's meaning and spending a significant amount of time on the word.

As most instructional strategies are structured around first language vocabulary acquisition, second language vocabulary instructional practices needed much scaffolding in the form of realia, verbal and visual cues, body language, among other things, to accommodate the apparent lack of tacit knowledge of the language that native speakers have.

\section{Vocabulary meaning episodes}

Translation: Translation of English words into isiXhosa, the HL of both the teachers and learners, was the most prevalent vocabulary meaning episode. Translation afforded acquisition of word meanings directly from an already known HL equivalent. Learners' familiarity and knowledge of the meaning of the HL equivalent would transfer to the novel word in English. The bulk of the translations were of decontextualised words as in Beauty's Uthetha ukuthini uvisited? Ukuhambela or Anne's Imountain yintaba andithi? (where the words mountain and ntaba were juxtaposed five times to enhance understanding). In such instances, there were clear one-to-one correspondence between the English and isiXhosa words. In fewer instances, translations were made on a whole sentence leaving the learners to work out which word in English corresponded with which one in isiXhosa. An example of such from Carol is 'what is the difference between these books? Yintoni umahluko phakathi kwezincwadi, nazi incwadi? In such instances, the assumption was that some of the English words and their isiXhosa equivalents were already known and the novel word 'difference', as can be assumed here, would be related to the word 'umahluko'. While such contextualised and indirect translations enhanced global understanding of the utterance, they could have minimal effect on vocabulary development where learners could not establish which word in the target language corresponded with which in the HL. A compromise between decontextualised and contextualised translation would be where the translation of the sentence would be followed by an explicit isolation of the words concerned in both languages, which was not manifest among the three teachers.

Synonym or antonym: Direct and indirect use of synonyms was employed by all three teachers to mediate word meaning. An example of the use of direct synonym was Beauty's 'huge means the same as big' and its effectiveness depended on one of the words (big) being known. In the single instances where direct synonym was used by each of the three teachers in the observed classes, only one synonym of the target word was given. Indirect or implied synonyms facilitated comprehensibility of utterances more than they did the understanding of novel words as learners needed to identify which known words corresponded with which novel ones. For instance, Carol's '[W]rite some key words, the important words that we...' left the inference of the words being juxtaposed to the learners, a feat that was aggravated by the absence of any emphasis or repetition of the synonymous words.

Contextual word use: Contextual word use made word meanings apparent, as in Anne's example 'brushing. Brushing (with learners repeating after the teacher). We brush our teeth everyday'. The initial repetition of the word 'brush' was meant to draw attention to it before the sentence to illustrate its use. The contextual word use strategy was normally preceded by some strategy be it a flagging strategy, as in this case, or a vocabulary episode like giving the synonym or direct explanation of the word. In all the contextual word uses, the teacher illustrated word use only once.

Analogy: Analogy was used once by Carol and once by Beauty in the examples 'A pool is similar to a dam' and 'snow is ice which falls as rain', respectively, in the observed lessons. 
The assumption was that 'dam' and 'ice' were the more familiar terms that could facilitate the understanding of the terms 'pool' and 'snow'.

Non-verbal demonstrations of word meaning: Non-verbal demonstrations included the use of visual or concrete media to mediate learner word knowledge. Anne's physical demonstration of the meaning of 'slow' and 'fast' in the statement 'When you walk fast, you walk like this, but when you walk slow you just walk like this' is a case in point. In another instance, Beauty asked learners to demonstrate knowledge of the word 'swim' by miming the art of swimming. Non-linguistic representation was meant to make word meanings apparent. Although Carol used drawings to teach words with-oo- letters, some drawings were too vague to bring clarity to some word meanings. Examples of such are drawings of sofas, table and chair that were supposedly meant to represent the word 'room' when 'furniture' was more appropriate, the shape of the sun used to explain the word 'noon' and 'zoo' being represented by a bus with passengers as well as an elephant and rhino nearby. Such ambiguities in representations detracted from the purpose they were intended to serve.

Direct word explanations: Direct explanations were evident from the prefacing word explanation with 'The word $X$ means...' or ' $X$ is...', It was supposed to be apparent that such phrases were precursors to the word meaning embodied in the later part of the utterance. Word meaning was given explicitly and learners were not required to infer it from contextual use. Carol's example was 'Past tense is the verb we use when something has already happened'. Direct word explanation was mainly employed for defining word classes like nouns, tenses, verbs that could not be accommodated by other strategies.

\section{Discussion}

Loud repetition of words helped to match sounds to words, thereby enhancing word transfer to long-term memory (Woo \& Price 2015). While seven-word flagging strategies were manifest, they were quite superficial to boost both retention and retrieval as not much intellectual engagements with the words was done beyond parroting them in isolation after the teacher without deliberately recycling them in subsequent lessons or contexts.

In both repeated word reading and repeated word spelling, for instance, it was not clear whether a run-down of a list of words ranging from 8 to 23 would entrench either their graphology or phonology in the learners. Spaced repetition within given intervals was not built into the strategies. Whether reliance on choral reading for both word spelling and word reading maximised gainful learner engagement, as would paired or partner reading or individual reading, was equally questionable considering that learners congested themselves around the board during repeated word reading or spelling. Exclusive utilisation of choral reading meant teachers related to learners as a homogeneous group. While choral reading is good for modelling pronunciation, that the teachers were themselves non-native speakers did not always accord learners this benefit. The overuse of choral reading on a long list of words within a single lesson brought monotony and consequently learner inattention. No strategies were used in conjunction with choral reading to break the monotony. There also was no assurance that individual learners could identify the words as whole class instruction was not complemented by small group and individual instruction, practice and assessment.

The few flagging strategies lacked variation. While repeated word saying and word reading was largely premised on the assumption that the more a word was repeated, the more it formed new networks of neurons and the better its retention and retrieval would be, re-reading of words in phrases, which Han and Chen (2010) see as affording development of word knowledge within macro (encyclopaedic) and micro (linguistic) contexts, could have been used. Word spelling variations in the repeated spelling strategy could have been used. While repetition increases familiarity, automatic word identification in repeated word reading in isolation does not guarantee automatic word identification in context. Successful reading depends not only on accurate word recognition, but also on automatic word recognition occasioned by the cumulative effect of the repetitions until the brain recognises the word without any deliberate effort on the reader's part. Repetition would have been effective if focus was on memorising and practising learnt words and not necessarily as a monotonous drill with no conscious effort to retain the word in memory.

Vocabulary development was a preserve of the teacher who assumed the role of causers of learning. This explains the absence of peer instruction in small groups, absence of deliberate instruction in word learning strategies and absence of opportunities to practise the learnt words. Less Englishproficient learners were denied opportunities to interact with more proficient peers. Learners, consequently, did not develop autonomy in learners' word learning. This vindicated Alexandra's (2013) observation that teachers are more concerned about their teaching than learners' learning. The teachers' roles were more didactic than facilitative.

The choice of words taught explicitly was, in the majority of cases, only based on one criterion, that is, words that were in the passage for the week. There was no apparent pattern manifest in the list of words isolated for instruction. Words learners needed to make general conversations, to respond to routine instructions, to engage in particular classroom experiences, which they had greater likelihood to practise within and beyond the classroom, were not prioritised. Even the fact that the mind naturally clusters connected words together was not taken into account. The learners' varied vocabulary needs were neither interrogated nor consulted.

Ostovar-Namaghi and Malekpur (2015) chronicle Oxford's (1990) taxonomy of language learning strategies, namely 
determination, social, memory, cognitive and metacognitive. Of these strategies, only cognitive strategies, dealing with mechanical rather than mental processing of words, were manifest in the form of word repetitions. Contextual determination of word meanings, word parts, word classes or dictionary work (determination strategies), asking for word meanings from knowledgeable others like the teacher or proficient peers (social strategies), recalling vocabulary learnt (memory strategies) and strategies for monitoring and assessing own progress (metacognitive strategies) were conspicuously absent in the teachers' practices. Social and determination strategies would have allowed learners some measure of autonomy in vocabulary acquisition. These are the discovery strategies (Tanyer \& Ozturk 2014). The other strategies were consolidation strategies meant to retain words already encountered.

Teacher-learner relationships observed were consistent with those obtained in typical United States classrooms, both public and private across grade levels where:

The typical student interacted with their teacher (individually or in a small group) fewer than four times in an hour, and in most cases, these exchanges were perfunctory and compliancedirected. (Pianta, Hamre \& Allen 2012:368).

There is a need for a balance in which the teacher guides but does not relegate the vocabulary acquisition process to learners or make it dependent on her. No self-regulated vocabulary learning behaviour was evident.

Three dimensions of lexical competence are word form, word meaning and word use. The documented explicit vocabulary development practices seemed to stagnate at the word form dimension and not go further to the word meaning and word use dimensions. Learners did not do much with the words that were isolated. No opportunities were given to manipulate, think about, talk about, apply and play with the new words. Christ and Wang (2010) emphasise offering opportunities to use newly learnt words that was generally lacking among most teachers' practices. They were not given tasks requiring them to practise vocabulary learnt. There were no remedial or extension activities despite the apparent diversity in the class. Activities that were done with words hardly required deep cognitive engagement to allow for deep processing that would have allowed for better retention of vocabulary learnt.

There were no lessons devoted solely to vocabulary instruction and the longest part of the lesson that was exclusively about vocabulary instruction was $8 \mathrm{~min}$ by Anne going over the repeated reading of 13 words. Vocabulary instruction was, in almost all cases, a precursor to the reading of a passage and the purpose was to ease the identification of the word in context. When the words were encountered in context, no attempt was made to draw learner attention to the words.

\section{Conclusion and recommendations}

For a duration of five 45-min English FAL lessons observed, the range of both quantity and recycling of English vocabulary exposure and that of 'flagging' strategies and vocabulary episodes was quite limited and limiting. This was aggravated by the absence of instruction in vocabulary learning strategies. Only so much could be achieved by learners relying solely on the teachers for vocabulary development. The English vocabulary development pedagogical practices manifest in Grade 3 English FAL classes were those largely meant to draw learners' attention to novel words without doing much to entrench the words in learners' memories and to require their retrieval, explanation and use by the learners. The nature of the manifest vocabulary development practices, which hardly empowered learners to be independent English vocabulary acquirers, could hardly develop sufficient lexical knowledge among Grade 3 learners, requisite for transition to Grade 4. Only the word consciousness aspect of the envisaged comprehensive vocabulary instruction programme received some considerable attention in the teachers' manifest practices.

In light of these observations, the study recommends the need for clearly marked vocabulary lessons that would compel teachers to think deliberately about learners' vocabulary needs and teachers' vocabulary development and assessment practices. There is a need for varied practices that go beyond learners echoing teachers' word reading and word saying that translates to vocabulary learning being a mechanical rather than a cognitive process.

\section{Acknowledgements}

We acknowledge and are grateful to the contributions from the Cape Consortium Strengthening Foundation Phase Research Programme for negotiating access into the schools at the provincial, district and school levels, and the consortium team for providing a collaborative space in which we could develop this study. Many thanks go to Sarah Murray for the guidance she provided, to Sally Hunt for introducing us to the AntConc software program and to Jonathan Jackson who did the language editing. We acknowledge the contribution of Anna, Gladys and Thobeka who were the research assistants in the field.

\section{Competing interests}

The authors declare that they have no financial or personal relationships that may have inappropriately influenced them in writing this article.

\section{Authors' contributions}

J.S. conducted the research and did the final writing up and J.B. made conceptual and theoretical contributions to the papers. The authors jointly analysed the findings.

\section{References}

Alexandra, G., 2013, 'Towards a learner-centred approach to teaching English', Professional Communication and Translation Studies 6(1-2), 205-210.

Biemiller, A., 2005, 'Size and sequence in vocabulary development: Implications for choosing words for primary grade vocabulary instruction', in A. Hiebert \& $\mathrm{M}$. Kamil (eds.), Teaching and learning vocabulary: Bringing research to practice, pp. 223-242, Erlbaum, Mahwah, NJ. 
Christ, T. \& Wang, X.C., 2010, 'Bridging the gap: What research tells us about vocabulary instruction in early childhood', Young Children 65(4), 84-91.

Department of Basic Education (DBE), 2011, Curriculum and Assessment Policy Statement, Government Printer, Pretoria.

Department of Basic Education (DBE), 2016, Education Statistics in South Africa 2014 Government Printer, Pretoria. Grabe, W. \& Stoller, F.L., 2011, 'Teaching and researching reading, 2nd edn., Routledge, New York.

Graves, M.F., 2006, The vocabulary book: Learning and instruction, Teacher's College, New York.

Green, B. (ed.), 2009, Understanding and researching professional practice, Sense, Rotterdam.

Han, Z.H. \& Chen, C.A., 2010, 'Repeated-reading-based instructional strategy and vocabulary acquisition: A case study of a heritage speaker of Chinese', Reading in a Foreign Language 22(2), 242-262.

Hinkel, E., 2007, Academic writing and how to grow vocabulary, TESOL, Seattle, WA, viewed 08 June 2016, from www.EliHinkel.Org/TESL2014

Hirsch, E.D., 2003, 'Reading comprehension requires knowledge-of words and the world', American Educator 27(1), 10-29.

Howie, S., Venter, E., Van Staden, S., Zimmerman, L., Long, C., Sherman, V. et al., 2008 PIRLS 2006 Summary report: South African children's reading literacy achievement, Centre for Evaluation and Assessment, Pretoria.

Joe, A., 2010, 'The quality and frequency of encounters with vocabulary in an English for academic purposes programme', Reading in a Foreign Language 22(1), 117-138.

Kemmis, S., 2009, 'Understanding professional practice: A synoptic account', in B. Green (ed.), Understanding and researching professional practice, pp. 19-38, Sense, Rotterdam.

Krügel, R. \& Fourie, J.E., 2014, 'Concerns for the language skills of South African learners and their teachers', International Journal of Educational Sciences 7(1) 219-228. https://doi.org/10.1080/09751122.2014.11890184

Koizumi, R., 2012, 'Relationships between text length and lexical diversity measures: Can we use short texts of less than 100 tokens?', Vocabulary Learning and Instruction 1(1), 60-69. https://doi.org/10.1080/09751122.2014.11890184

Laufer, B. \& Hulstijn, J.H., 2001, 'Incidental vocabulary acquisition in a second language: The construct of task-induced involvement', Applied Linguistics 22 1-26. https://doi.org/10.1093/applin/22.1.1
Linse, C.T., 2005, Practical English language teaching young learners, McGraw-Hill, New York.

Nagy, W.E., 2005, 'Why vocabulary instruction needs to be long-term and comprehensive', in E.H. Hiebert \& M.L. Kamil (eds.), Teaching and learning vocabulary: Bringing research to practice, pp. 27-44, Lawrence Erlbaum, Mahwah, NJ.

Nel, N. \& Muller, H., 2010, 'Using English as a second language of instruction: Concerns and needs of primary school in South Africa', South African Journal of Education 30(4), 635-650. https://doi.org/10.15700/saje.v30n4a393

Ostovar-Namaghi, S.A. \& Malekpur, A., 2015, 'Vocabulary learning strategies from the bottom-up: A grounded theory', The Reading Matrix: An International Online Journal 15(2), 235-251.

Pianta, R.C., Hamre, B.K. \& Allen, J.P., 2012, 'Teacher-student relationships and engagement: Conceptualizing, measuring, and improving the capacity of classroom interactions', in S.L. Christenson (ed.), Handbook of student engagement, pp. 365-386, Guildford, New York.

Schatzki, T.R., 2002, The site of the social: A philosophical account of social life and change, Penn State University Press, University Park, PA.

Sibanda, J., 2017, 'Extent of the utilisation of vocabulary learning opportunities from classroom print', International Journal of Education Sciences (IJES) 16(1-3), 138-151.

Sibanda, J. \& Baxen, J., 2016, 'Determining ESL learners' vocabulary needs from textbook corpus: Challenges and prospects', Southern African Linguistics and Applied Language Studies 34(1), 57-70. https://doi.org/10.2989/16073614.2016.1159521

Tanyer, S. \& Öztürk, Y., 2014, 'Pre-service English teachers' vocabulary learning strategy use and vocabulary size: A cross-sectional evaluation', Journal of Language Teaching and Research 5(1), 37-45. https://doi.org/10.2989/16073614.2016.1159521

Texas Reading Initiative, 2002, Promoting vocabulary development: Components of effective vocabulary instruction, rev. edn., Texas Education Agency, Austin, TX.

Woo, M. \& Price, R., 2015, 'The pronunciation-reading connection', in T. Jones (ed.), Integrating pronunciation with other skills areas, TESOL Press, Alexandria, VA.

Wright, T.S., 2012, 'What classroom observations reveal about oral vocabulary instruction in kindergarten', Reading Research Quarterly 47(4), 353-355.

Zhu, N., 2015, 'Cognitive strategy instruction for mathematical word problem solving of students with mathematics disabilities in China', International Journal of Disability Development and Education 62(6), 608-627. https://doi.org/10.1080/1 034912X.2015.1077935 